\title{
Fuentes gráficas para el estudio de tres edificios históricos de Sevilla: las plantas de los conven- tos de la Santísima Trinidad, San Francisco de Paula y San Pedro de Alcántara ${ }^{1}$
}

\author{
Alberto Fernández GonZÁLEZ \\ Universidad de Sevilla
}

RESUMEN: A raíz de las leyes desamortizadoras de 1835, y en previsión de su posible transformación en cuarteles, el coronel ingeniero Benito León y Canales levantó las plantas de varios monasterios sevillanos. El hallazgo en el Archivo General Militar de Madrid de los planos correspondientes a los conventos de la Santísima Trinidad, San Francisco de Paula y San Pedro de Alcántara ha permitido documentar, por primera vez, la exacta distribución de sus plantas.

Palabras clave: Benito León y Canales, Planos, Convento de San Francisco de Paula, Monasterio de la Trinidad, Convento de San Pedro de Alcántara, Sevilla, Arquitectura religiosa, Siglo XIX.

ABSTRACT: As a result of the Ecclesiastical Confiscations of Mendizábal in 1835, and in anticipation of their possible change into headquarters, Colonel Engineer Benito León y Canales drew up the ground plans for several monasteries in Seville. The finding of the plans of the convents of the Holy Trinity, Saint Francis of Paola and Saint Peter of Alcantara in the General Military Archives has allowed us to document the exact distribution of these building's ground plans for the first time.

Key Words: Benito León y Canales, Plans, Convent of Saint Francis of Paola, Monastery of the Holy Trinity, Convent of San Peter of Alcantara, Seville, religious architecture, 19th Century.

A lo largo de los siglos XIX y XX, en varias etapas, la ciudad de Sevilla sufrió la destrucción de gran parte de su patrimonio arquitectónico. La pérdidas patrimoniales

${ }^{1}$ Este artículo se ha llevado a cabo con una ayuda del Vicerrectorado de Investigación de la Universidad de Sevilla, que fue concedida para realizar una estancia de investigación en varios archivos de Madrid durante los meses de julio y agosto de 2011. del ochocientos se iniciaron en 1810 con la invasión francesa y continuaron con las sucesivas desamortizaciones de los años treintas de la centuria. Entre noviembre y diciembre de 1835, a raíz precisamente de los primeros decretos de exclaustración, el coronel ingeniero Benito León y Canales levantó las plantas de varios conventos hispalenses que 
se proyectaban transformar en cuarteles ${ }^{2}$. Aunque los planos del antiguo monasterio de la Merced Calzada, hoy Museo de Bellas Artes de Sevilla, y del convento del Pópulo, desaparecido, se publicaron en su momento $^{3}$, no se conocían, hasta ahora, más levantamientos del ingeniero militar. El hallazgo, en el Archivo General Militar de Madrid, de los planos correspondientes a los conventos de la Santísima Trinidad, San Francisco de Paula y San Pedro de Alcántara, también trazados por León y Canales, ha supuesto un gran avance en el conocimiento de estos tres históricos edificios ya que se ha podido documentar, por primera vez, su exacta distribución en planta. Es más, los tres levantamientos del técnico militar adquieren una gran relevancia como fuentes gráficas para el estudio de este importante patrimonio

\footnotetext{
${ }^{2}$ Sobre la biografía de Benito León y Canales se puede precisar que ingresó en el cuerpo de ingenieros en 1813, que recibió dos cruces de San Fernando de primera clase por sus méritos y que su último destino fue en Granada, en la Dirección-Subinspección de Andalucía (J. CARRILLO DE ALBORNOZ, “La Real y Militar Orden de San Fernando y el Arma de Ingenieros (II)", Memorial del Arma de Ingenieros, $\mathrm{n}^{\circ}$ 64, 2001, p. 158). Sobre la historia del cuerpo de ingenieros, su estructura institucional y la formación científica que recibían los técnicos, véanse $\mathrm{H}$. CAPEL, J. SÁNCHEZ y O. MONCADA, De Palas a Minerva, Barcelona, 1988.
}

${ }^{3}$ La planta del monasterio de la Merced Calzada fue dada a conocer por J. M. SUÁREZ GARMENDIA, "La formación de plazas en Sevilla a mediados del siglo XIX", Archivo Hispalense, no 192, 1980, pp. 239-259; sobre ella volvió V. PÉREZ ESCOLANO, “El convento de la Merced Calzada de Sevilla (actual Museo de Bellas Artes) a la luz de la relación de fray Juan Guerrero (mediados del siglo XVII) y la planta aproximada de 1835", en Homenaje al Profesor Doctor Hernández Díaz, Sevilla, 1982, vol. I, pp. 545-561; y muy recientemente A. FERNÁNDEZ GONZÁLEZ y M. VARAS RIVERO, "La arquitectura dibujada: los conventos sevillanos de la Encarnación, el Pópulo y la Merced Calzada según planos del siglo XIX", Archivo Hispalense, no 288-290, 2012, pp. 175-198. Aunque la planta del convento del Pópulo se publicó parcialmente en A. COLLANTES, J. CRUZ, R. REYES y S. RODRÍGUEZ (Dirs.), Diccionario histórico de las calles de Sevilla, Sevilla, 1993, pp. 66-67, fue estudiada por A. FERNÁNDEZ GONZÁLEZ y M. VARAS RIVERO, Op. Cit. arquitectónico desaparecido ${ }^{4}$, pues el antiguo cenobio trinitario sufrió múltiples remodelaciones con posterioridad a 1835 que alteraron radicalmente su estructura, y los históricos edificios de los mínimos y los alcantarinos fueron demolidos en el siglo XIX, salvo sus respectivas iglesias y la capilla de la Orden Tercera, que pertenecía al convento de San Pedro de Alcántara, las únicas estructuras que se conservan de las primitivas clausuras.

Antes de estudiar las plantas, me gustaría considerar brevemente el sistema gráfico de representación utilizado por Benito León y Canales. Sobre el papel, que es el soporte empleado, los tres edificios se dibujan con el mismo procedimiento gráfico: para definir las líneas arquitectónicas, se utiliza tinta roja, y, para representar los espacios abiertos, colores a la aguada. La variación de textura también se aprecia en el entorno urbano, en las diferentes manzanas de casas próximas a los monasterios. Con objeto de facilitar la identificación de las piezas que componen la clausura, se emplea un sistema alfanumérico que es explicado en un pequeño abecedario que figura a la izquierda del documento gráfico. Pero además de letras y números, se incluyen anotaciones complementarias que señalan las calles y aclaran todavía más la exacta distribución de los edificios. Se registra la fecha de realización, el nombre del convento representado, el autor del plano y el visto bueno de Sierra, un técnico militar de rango superior. Lleva también escala en varas.

\section{LA PLANTA DEL CONVENTO DE LA SANTÍSIMA TRINIDAD}

La llegada de los trinitarios a Sevilla se remonta a 1248 , fecha de la conquista

\footnotetext{
${ }^{4}$ Sobre el papel que pueden desempeñar los mapas, planos y dibujos como complemento del análisis y conocimiento de los procesos transformadores que sufren los edificios o la propia trama urbana de la ciudad, véase el reciente monográfico que el Instituto Andaluz del Patrimonio Histórico ha dedicado al tema: revista $p h, \mathrm{n}^{\mathrm{o}}$ 77, febrero 2011.
} 
de la ciudad por Fernando III el Santo 5 . La orden, muy popular por su dedicación a la redención de cautivos cristianos y su labor hospitalaria, funda su sede hispalense dos años más tarde, en un amplio solar situado fuera de los muros de la ciudad, frente a la Puerta del Sol. Como el edificio conventual se levantó sobre las legendarias cárceles donde, según la tradición, estuvieron recluidas las mártires y patronas de Sevilla Justa y Rufina, el cenobio trinitario también se conocía con el nombre de las santas. En 1253, Alfonso X el Sabio confirma la fundación y dona al monasterio varias posesiones que incrementaron sus rentas ${ }^{6}$. La iglesia actual se fecha en el primer tercio del siglo XVII, siendo su diseño realizado por fray Miguel de Peñalosa, que contó con el asesoramiento del arquitecto mayor de la catedral de Sevilla, Miguel de Zumárraga ${ }^{7}$. La llegada de los invasores franceses a la ciudad en febrero de 1810 supuso la expulsión de los religiosos y el saqueo de su importante patrimonio artístico ${ }^{8}$. Los monjes regresan al convento en 1818 y durante casi dos décadas realizan las labores propias de su institución. En 1835, a raíz de la aplicación de las leyes desamortizadoras ${ }^{9}$, los trinitarios abandonan para siempre su histórica sede hispalense, y el edificio se remodela y transforma en cuartel

${ }^{5}$ D. ORTIZ DE ZÚÑIGA, Anales eclesiásticos y seculares de la muy noble y muy leal ciudad de Sevilla, metrópoli de la Andalucía, Sevilla, 1988 (ed. facsímil de la ed., Madrid, 1795-1796), vol I, pp. 49, 80-81.

${ }^{6}$ A. MORGADO, Historia de Sevilla, Sevilla, 1887 (1 $1^{\text {a }}$ ed., Sevilla, 1587), pp. 387-388.

${ }^{7}$ J. A. ARENILLAS, Del Clasicismo al Barroco. Arquitectura sevillana del siglo XVII, Sevilla, 2005, pp. 147-149.

${ }^{8}$ Para conocer, en detalle, el importante patrimonio artístico del monasterio, véase la reciente síntesis de M. FERNÁNDEZ ROJAS, Patrimonio artístico de los conventos masculinos desamortizados en Sevilla durante el siglo XIX: trinitarios, franciscanos, mercedarios, jerónimos, cartujos, mínimos, obregones, menores y filipenses, Sevilla, 2009, pp. 16-30.

${ }^{9}$ Sobre el progreso de la exclaustración, que quedará ligado íntimamente a la vida política del país, la guerra carlista y las luchas internas entre liberales moderados y progresistas, véase M. REVUELTA, $L a$ Exclaustración (1833-1840), Madrid, 2010, pp. 361-396. de artillería ${ }^{10}$. A pesar de las graves alteraciones que sufrió su arquitectura, lo que ha permanecido del histórico monasterio, que desde 1882 pertenece a la congregación de sacerdotes salesianos, fue declarado en 1964 Monumento Histórico-Artístico.

El famoso plano de Sevilla levantado por Francisco Coelho y grabado por Joseph Amat que mandó realizar el asistente Pablo de Olavide en 1771 documenta la exacta ubicación del convento de la Santísima Trinidad (Fig. 1). Rodeado por extensos campos, se distingue perfectamente el edificio al nordeste de la ciudad, fuera de las murallas medievales y no muy alejado del prado de Santa Justa, que se localiza al este, y la Puerta del Soll ${ }^{11}$, emplazada hacia el suroeste.

Mucho más relevante, desde luego, por ser la única fuente gráfica detallada que se conoce del antiguo cenobio trinitario, es el levantamiento de Benito León y Canales (Fig. 2) que custodia el Archivo General Militar de Madrid ${ }^{12}$. El plano del ingeniero militar se fecha en diciembre de 1835, poco después de la salida de los monjes, y describe, por tanto, la exacta distribución en planta que tenía el histórico monasterio, antes de las sucesivas remodelaciones que adaptaron sus espacios a las necesidades castrenses. La portada principal del edificio (letra A), como ocurre en la actualidad, se localiza en el flanco sur del complejo monacal. Una vez superada la entrada, y siguiendo un enorme

${ }^{10}$ M. PONCE ORTIZ DE INSAGURBE y J. SÁNCHEZ SÁNCHEZ, Sevilla: arquitectura y ciudad militar, Sevilla, 2004, pp. 204-205.

${ }^{11}$ En las proximidades de la Puerta del Sol existía un postigo que permitía a los monjes, a todas horas, entrar y salir de la ciudad; era uno de los muchos privilegios que tenía la comunidad trinitaria. $\mathrm{Al}$ respecto, véase F. GONZÁLEZ DE LEÓN, Noticia artística de todos los edificios públicos de esta muy noble ciudad de Sevilla, Sevilla, 1973 (1ํㅡㄹ ed., Sevilla, 1844), p. 514.

${ }^{12}$ Archivo General Militar de Madrid (en adelante AGMM.). Fondo Se-7-5. Planta del convento de la Trinidad extramuros de Sevilla. 
compás de acceso $^{13}$ (letra $C$ ), que hoy se ha transformado en atrio abierto, se llegaba al templo conventual ("Yglesia"), dispuesto en eje con el pórtico principal, y a la portería (letra $\mathrm{B}$ ), situada al este, que era preciso atravesar si se quería ingresar en la clausura. El largo lienzo de muralla que se orientaba hacia la Puerta del Sol se distingue perfectamente en el plano de 1835; en la tapia figura también delineada una segunda puerta que daba a la huerta del monasterio (no 6). Los frailes trinitarios disponían de un pequeño jardín ( $\mathrm{n}^{\mathrm{o}} 8$ ) de recreo que estaba cercado por el muro oriental del compás de entrada, el lienzo oeste del zaguán de acceso a las extensas plantaciones de los monjes ("Huerta") y la pequeña estructura funcional identificada por León y Canales como "casa de hortelanos" $\left(\mathrm{n}^{-} 7\right)$.

El levantamiento del ingeniero militar reproduce la planta rectangular del templo construido en el primer tercio del siglo XVII ${ }^{14}$ ("Yglesia"). Se constata su portada, que se localiza a los pies de la iglesia y enlaza con el compás de entrada, su única nave y la amplia sacristía ubicada detrás del presbiterio, con el que mantenía directa comunicación, a través de las dos entradas dispuestas a los lados del altar mayor ${ }^{15}$. No aparecen dibujadas, sin embargo, ni las capillas ni los re-

\footnotetext{
${ }^{13}$ Aunque no aparece recogida en el plano del ingeniero, pues en 1835 ya había desaparecido, existía tiempo atrás, junto a la primera puerta de entrada al compás, una pequeña capilla que se había edificado hacia 1404, en memoria y desagravio del sacrílego robo de la custodia del templo. Al respecto, véase F. GONZÁLEZ DE LEÓN, Op. Cit., p. 514.

${ }^{14}$ Sobre la iglesia del convento, véanse A. MORALES, M. J. SANZ, J. M. SERRERA y E. VALDIVIESO, Guía artística de Sevilla y su provincia, vol. I, Sevilla, 2004 (1aㅡ ed., Sevilla, 1981), pp. 295-296; F. CRUZ ISIDORO, Arquitectura sevillana del siglo XVII. Maestros mayores de la catedral y del concejo hispalense, Sevilla, 1997, pp. 44-45; y J. A. ARENILLAS, Op. Cit., pp. 147-151.

${ }^{15}$ En la vicaría se guardaban importantes reliquias, entre ellas, las de las santas Justa y Rufina. Al respecto, véase F. GONZÁLEZ DE LEÓN, Op. Cit., p. 513.
}

tablos que algunos años más tarde, en 1844, concretamente, describe González de León ${ }^{16}$.

Por el doble acceso de la portería que regula la entrada a la clausura (letra $B$ ), se llega a un vestíbulo que da paso a un tránsito (letra E) que enlaza con el corredor occidental (letra D) del claustro principal ("Patio") y conecta también con otro tránsito (letra E) que conduce a un pequeño claustro ("Patio") situado en el flanco norte del complejo monacal, donde se disponen algunas celdas de los monjes ( $\mathrm{n}^{\mathrm{o}} 2$ ). Este largo pasilloque corre contiguo al muro exterior de la epístola establece en realidad un fundamental eje distributivo del edificio que conecta la portería con las escaleras que aparecen dibujadas justo al lado de la sacristía, por las que se descendía hasta la denominada Fuente del Arzobispo ${ }^{17}$, y que enlaza, además, los dos edificios claustrales, el principal y el pequeño, y permite también el acceso directo, desde el interior de la clausura, a la iglesia y la sacristía, a través de las dos puertas laterales que recoge el documento gráfico. Aunque los espacios del histórico monasterio se han modificado, el largo corredor que se aprecia en el plano de 1835 todavía se conserva hoy en día, y sigue desempeñando en el actual edificio de los salesianos su primitiva función distributiva, pues conecta el templo -mediante la referida puerta lateral, que también permanece- con lo que en su momento había constituido el claustro principal -hoy parcialmente conservado- y con el actual patio de recreo, antes claustro pequeño.

En el flanco norte del claustro principal se ubican los dormitorios anteriormente referidos $\left(n^{-} 2\right)$ que tenían su entrada por el patio secundario, y otra estancia contigua, algo más grande, que también albergaba habitaciones en su interior ( $\left.n^{-} 2\right)$ y tenía su puerta de acceso por el claustro principal ${ }^{18}$;

\footnotetext{
${ }^{16}$ Idem, pp. 511-513.

${ }^{17}$ Idem, p. 509.

${ }^{18}$ En el costado norte del patio principal, existía "una puerta con reja que da entrada y luz a una escalera que baja a las cárceles donde estuvieron presas las santas patronas de la ciudad Justa y Rufina" (Ibidem).
} 
en el sector oriental, se localiza la "Sala de Profundis" (n⿳⺈ 1); y en el lado sur del edificio claustral, se emplaza el refectorio (no 3 ), pieza que sirve de enlace estructural con el tercer claustro ("Patio") que verifica la planta de León y Canales. Este último edificio claustral organiza la distribución de las dependencias más funcionales del convento: a su alrededor se disponen las cocinas $\left(n^{-} 4\right)$, que tenían puerta de comunicación directa con el "Corralon" ( $n^{0}$ 5), y las demás estancias de servicio; pero acoge también a otros seis dormitorios ( $\left.\mathrm{n}^{\mathrm{o}} 2\right)$, de menores dimensiones, eso sí, que daban a los corredores sur y oeste. El referido "Corralon" ( $\left.n^{-} 5\right)$, que abarca un enorme espacio comprendido entre los flancos norte y este del edificio y sus correspondientes muros exteriores de cerramiento, tal como documenta el plano del ingeniero militar, estaba aislado de las distintas piezas que estructuraban la clausura, pues enlaza únicamente con un pequeño cuarto dispuesto en el ángulo suroriental de la cerca (no 9) y con la huerta, a través de dos puertas que se localizan en los flancos septentrional y meridional ( $\mathrm{n}^{\mathrm{o}}$ 10) del muro exterior.

\section{LA PLANTA DEL CONVENTO DE SAN FRANCISCO DE PAULA}

En 1589 el arzobispo cardenal Rodrigo de Castro y el cabildo de la ciudad otorgaron las correspondientes licencias para el establecimiento del colegio de San Francisco de Paula, que se instaló en la collación de San Lorenzo, "en unas casas de la calle de las Palmas", hoy Jesús del Gran Poder ${ }^{19}$. Aunque no se conocen muchos datos relativos a la historia constructiva del convento-colegio, se puede fechar el comienzo de las obras en los primeros años del siglo XVII ${ }^{20}$. Al llegar las tropas napoleónicas en 1810, como había ocurrido con otros conventos de Sevilla, los religiosos son exclaustrados y el edificio es

${ }^{19}$ D. ORTIZ DE ZÚÑIGA, Op. Cit., vol. IV, p. 144.

${ }^{20}$ Una síntesis con los escasos datos que se conservan al respecto en M. FERNÁNDEZ ROJAS, Op. Cit., pp. 451-452. Véase también J. A. ARENILLAS, Op. Cit., pp. 151-152. expoliado y ocupado. El viejo cenobio de los mínimos, a raíz de la aplicación de las leyes desamortizadoras de 1835, se transforma en cuartel de la milicia urbana de Caballería, albergando más tarde, en 1868, un regimiento de Artillería ${ }^{21}$. El gobierno revolucionario, ese mismo año de 1868, incauta la iglesia y la vende a la Sociedad Bíblica de Londres, que convirtió el antiguo templo franciscano en la primera iglesia protestante de la ciudad. Desde 1887, fecha en que Dolores Armero y Benjumea, piadosa y acaudalada dama sevillana, compra la iglesia y la entrega a los padres jesuitas, el templo pertenece a la Compañía de Jesús; pero el histórico convento de San Francisco de Paula, por desgracia, no se ha conservado ${ }^{22}$.

El referido plano de Sevilla que en 1771 mandó levantar el asistente Pablo de Olavide (Fig. 3) describe con precisión el área urbana que rodeaba al edificio. El cenobio de los mínimos ocupaba, como constata Francisco Coelho en su levantamiento, el sector septentrional de la gran manzana que se extendía desde la Alameda de Hércules a la calle de San Miguel. El frente norte del convento lindaba con la explanada de la Alameda, que abarcaba en ese momento más espacio urbano; su flanco sur, con viviendas de particulares; y las fachadas este y oeste daban, respectivamente, a la calle del Puerco, actual Trajano, y a la de las Palmas, hoy Jesús del Gran Poder.

El segundo plano hallado en el Archivo General Militar de Madrid ${ }^{23}$ (Fig. 4) describe pormenorizadamente la distribución del convento de San Francisco de Paula, tal como estaba compartimentado en noviembre de 1835. Según anota Benito León y Ca-

${ }^{21}$ M. PONCE ORTIZ DE INSAGURBE y J. SÁNCHEZ SÁNCHEZ, Op. Cit., p. 200.

${ }^{22} \mathrm{Al}$ respecto, véase M. FERNÁNDEZ ROJAS, “Los Mínimos en San Francisco de Paula en Sevilla durante los siglos XVI al XIX", en Los Mínimos en Andalucía, Almería, 2006, pp. 166-168. Sobre el templo conventual, véase J. A. ARENILLAS, Op. Cit., pp. 151-153.

${ }^{23}$ AGMM. Fondo Se-7-8. Planta del convento de San Francisco de Paula de Sevilla. 
nales a la izquierda del documento gráfico, "la situacion y disposicion de este edificio lo hacen a proposito para pabellones de los oficiales, sin que deje por esto de ser el punto de reunion de la Guardia Nacional de Caballeria a que esta hoy destinado". La planta levantada por el ingeniero militar permite constatar cuatro entradas (letra A). Hacia la Alameda de Hércules se orientaban dos accesos: la puerta principal, que comunicaba, mediante un amplio corredor, con tres piezas: el denominado "Portico de entrada al convento" (no 2), otra sala identificada como "Cuerpo de Guardia del oficial" ( $\mathrm{n}^{\mathrm{o}}$ 1) y una última estancia destinada a cuadras (letra D); y la puerta de servicio, que era una entrada secundaria localizada en el sector este de la fachada -donde tal vez en otro tiempo se ubicaba el pequeño claustro doméstico que mencionan las fuentes ${ }^{24}$ que permitía el acceso directo a las cocinas y demás piezas funcionales ( $n^{0} 5$ y 6 ). En este frente septentrional del edificio incluso aparece delineado un tercer paso que no se identifica como puerta de entrada porque daba a un espacio anexo pero aislado de la clausura que se describe como "Reñidero de Gallos". Otra puerta de entrada (letra A) al convento se sitúa en la calle de las Palmas, y mantiene una íntima conexión con el espacio antes referido que se destinaba a "Cuadra de Nacionales" (letra D), según especifica León y Canales. La última entrada (letra A) que figura en el levantamiento de 1835 se localiza hacia la calle del Puerco; es un vestigio estructural de la primitiva configuración de la iglesia del colegio, que tenía su acceso precisamente por la mencionada calle. La puerta, tal como constata el documento gráfico, enlaza con el "Compas" ( $\left.\mathrm{n}^{\mathrm{o}} 4\right)$, también resto estructural de la antigua distribución del edificio -aunque muy alterado por las sucesivas remodelaciones, el compás de entrada se conserva parcialmente todavía, y sigue facilitando un rápido acceso al templo, hoy iglesia de los jesuitas-, pieza que comunicaba, una vez superado un pequeño corredor cubierto, con la sacristía ( $n^{\circ}$ 3) y el presbiterio del templo

${ }^{24}$ M. FERNÁNDEZ ROJAS, Patrimonio artístico de los conventos masculinos desamortizados..., p. 453.
("Yglesia"). La sacristía, de planta cuadrangular, es, por cierto, la original del convento-colegio; se localizaba, como muestra el plano, en el lado del evangelio, próxima a la cabecera de la iglesia, y disponía, además, de una estancia contigua (no 3) que también era utilizada como vicaría.

El núcleo estructural del cenobio de los mínimos, como es habitual en este tipo de construcciones, lo determina la iglesia y el claustro principal. Del espacioso templo conventual Benito León y Canales dibuja únicamente su planta rectangular, así que no se puede establecer la exacta ubicación de las capillas que caían hacia el lado de la epístola $^{25}$. Las plantas de las dos capillas situadas en el lado del evangelio, "abiertas y comunicables por arcos", se distinguen perfectamente en el plano; y se constata también que ambas estructuras articulan la "corta nave" descrita por González de León ${ }^{26}$. La capilla emplazada a los pies del templo, que era propiedad de la hermandad de la Sagrada Lanzada ${ }^{27}$ y que años más tarde será segregada de la iglesia para ampliar con ella el interior del futuro cuartel de caballería ${ }^{28}$, se plasma asimismo en el dibujo del ingeniero militar. Justo al lado de esta capilla, figura delineada la entrada principal de la iglesia, que salía, como ocurre hoy en día, a la antigua calle de las Palmas. Paredaño al muro norte de las capillas situadas en el lado del evangelio, se localiza el claustro ("Patio").

${ }^{25}$ Tampoco figuran delineados los altares dispuestos en el lado del evangelio. $\mathrm{Al}$ respecto, véase $\mathrm{F}$. GONZÁLEZ DE LEÓN, Op. Cit., pp. 442-443.

${ }^{26}$ Idem, p. 442.

${ }^{27}$ La hermandad de la Sagrada Lanzada y María Santísima del Buen Fin se traslada a la iglesia en 1818 y mejora y amplía el espacio que en el siglo XVI había fundado la cofradía del Santísimo Cristo de la Sangre, Nuestra Señora de la Candelaria y San Juan Bautista (M. FERNÁNDEZ ROJAS, Patrimonio artístico de los conventos masculinos desamortizados..., p. 452). Sobre el estado que presentaba el templo a mediados del ochocientos, véase también P. MADOZ, Diccionario geográfico-estadístico-histórico de Andalucía. Sevilla, Valladolid, 1986 (ed. facsímil de la ed., Madrid, 1845-1850), p. 264.

${ }^{28}$ F. GONZÁLEZ DE LEÓN, Op. Cit., p. 443. 
El edificio claustral, bastante amplio, se estructura, como es habitual, mediante una serie de columnas y arcadas que organizan sus cuatro $\operatorname{costados}^{29}$; sus corredores (letra C) y las estancias contiguas, también se constatan en la planta. Pienso que la gran sala rectangular situada al norte del patio, por su lugar de emplazamiento y su directa comunicación con el claustro y el pórtico de entrada, podría corresponder al refectorio. $\mathrm{Al}$ este y oeste del edificio claustral se disponen los dormitorios (letra B), piezas con suficiente capacidad para albergar las celdas de los monjes, en especial la que ocupa todo el flanco occidental del claustro hacia la calle de las Palmas, donde también se localiza lo que parece ser la principal escalera de acceso al piso alto.

\section{LA PLANTA DEL CONVENTO DE SAN PEDRO DE ALCÁNTARA}

Promovido por el también monasterio sevillano de San Diego, cabeza de la antigua Provincia Bética, fue el de San Pedro de Alcántara el último convento franciscano fundado en la ciudad hispalense. Con la intención de crear un pequeño hospital donde atender a los religiosos de los cenobios más próximos, los alcantarinos, que pertenecían a la rama descalza de los frailes menores de San Francisco, compran unas antiguas casas de mayorazgo que los Ortiz de Zúñiga, marqueses de Valencina, tenían en la collación de San Andrés. Más tarde intentaron ampliar la enfermería y transformarla en convento, pero las autoridades eclesiásticas y el arzobispo Agustín de Spínola no aprobaron el proyecto. Los religiosos tuvieron que esperar hasta 1649, año marcado por la grave epidemia de peste que asoló la ciudad, para obtener el esperado permiso. No se conocen datos sobre la historia constructiva del convento-hospital, pero se sabe que la primera

\footnotetext{
${ }^{29}$ El claustro tenía dos pisos: el inferior se organizaba mediante arcadas y abría sus cuatro galerías al patio, donde se disponía una fuente muy baja a la que se descendía por cuatro gradas; el superior, por su parte, era cerrado y tenía balcones que daban al patio (Idem, p. 444).
}

misa se ofició en un pequeño templo que fue habilitado provisionalmente y que la iglesia del monasterio se inauguró, "con gran solemnidad", el 10 de otubre de $1666^{30}$. El edificio de los alcantarinos, en todo caso, tuvo dos funciones esenciales: la hospitalaria y la conventual. Con la llegada de los franceses en 1810, los religiosos fueron expulsados por primera vez de su clausura, como había ocurrido con los trinitarios, los mínimos y el resto de los cenobios masculinos de Sevilla, y el establecimiento fue utilizado como hospital. En 1813 regresan los monjes al convento, permaneciendo en él hasta la exclaustración general de 1835. Aunque se había contemplado la posibilidad de transformar el edificio en cuartel, circunstancia que dio lugar al levantamiento de Benito León y Canales, finalmente se dedicó a usos civiles: en tres sectores bien diferenciados se instalaron la denominada Escuela Normal, otra escuela gratuita de adultos y una fábrica de cerveza. La iglesia conventual permaneció abierta al culto hasta su incautación, en 1868, por la Junta Revolucionaria, que la habilitó como capilla del recién creado instituto de enseñanza San Isidoro; pero el convento, ya desde 1860, sufrió derribos parciales. Lo poco que quedaba de la clausura, salvo la iglesia y la capilla de la Orden Tercera, que todavía se conservan en pie, fue demolido en 1895, a fin de que la congregación femenina de las Esclavas del Sagrado Corazón de Jesús culminase su nueva residencia ${ }^{31}$.

Como recoge el varias veces aludido plano de Sevilla que mandó realizar el asistente Olavide en 1771 (Fig. 3), el conventohospital se insertaba en una amplia manzana de la collación de San Andrés. El área urbana que lo circunvalaba queda enmarcada en el levantamiento de Coelho por la calle de Santa María, que se ubica al norte;

${ }^{30}$ D. ORTIZ DE ZÚÑIGA, Op. Cit., vol. V, pp. 3-4, 60. Una reciente síntesis de la historia del convento en M. FERNÁNDEZ ROJAS, Patrimonio artístico de los conventos masculinos desamortizados..., pp. 233-235.

${ }^{31}$ J. GESTOSO Y PÉREZ, Sevilla Monumental y Artística, Sevilla, 1984 (ed. facsímil de la ed., Sevilla, 1892), pp. 315-316. 
la costanilla de San Andrés, localizada al sur; la vía que a partir de la fundación del convento pasó a llamarse calle de San Pedro de Alcántara, hoy rotulada Cervantes, que se sitúa al este; y por la calle del Amor de Dios, emplazada al oeste. El convento de San Pedro de Alcántara, tal como constata el tercer plano de Benito León y Canales hallado en el Archivo General Militar de Madrid $^{32}$ (Fig. 5), ocupaba en realidad el gran sector central del área urbana donde se insertaba. Sus flancos septentrional y meridional estaban rodeados por casas, pero de oriente a occidente abarcaba toda la anchura de la manzana, desde la calle de San Pedro de Alcántara a la del Amor de Dios. Aunque los monjes tenían acceso directo a esta última vía, a través de la denominada en el plano de 1835 "Puerta del Campo con su corral" ( $\mathrm{n}^{\mathrm{o}}$ 6), las dos entradas principales del convento (letra A) se localizan en la antigua calle de San Pedro de Alcántara, actual Cervantes. La puerta más septentrional corresponde a un acceso desconocido que comunicaba con un "Portico" (letra B) que enlazaba, a su vez, con la capilla de la Orden Tercera ${ }^{33}$, pieza que en el plano del ingeniero militar, curiosamente, se identifica como "Almacen"; con el compás de entrada (letra C) que facilitaba el acceso a la iglesia y la clausura; y con el templo conventual, mediante una puerta ubicada en el lado de la epístola. Inaugurada en 1696, la referida capilla de la rama seglar franciscana -hoy constituye el número 7 de la calle de Cervantes- manifiesta en el documento gráfico una planta casi rectangular, pues sólo su muro oriental, que se adapta a la línea oblicua de la calle, rompe el esquema regular ${ }^{34}$.

El segundo acceso que se localiza en la calle de San Pedro de Alcántara corresponde a la portada principal del monasterio(letra A), que permitía el ingreso directo en la

\footnotetext{
${ }^{32}$ AGMM. Fondo Se-7-9. Planta del convento de San Pedro Alcántara de Sevilla.

${ }^{33} \mathrm{Su}$ descripción artística figura en J. GESTOSO Y PÉREZ, Op. Cit., pp. 315-316.

${ }^{34}$ Sobre la iglesia, véanse F. GONZÁLEZ DE LEÓN, Op. Cit., p. 449; y P. MADOZ, Op. Cit., p. 262.
}

clausura y en el templo, una vez superado el aludido compás (letra C) que enlazaba también, según se ha explicado, con el referido pórtico (letra B) que antecedía a la capilla de la Orden Tercera. El levantamiento de León y Canales constata la planta rectangular del templo alcantarino ("Yglesia"). Del santuario, se aprecia claramente su única nave $\mathrm{y}$ el pequeño pórtico situado a los pies (letra B) que se articulaba mediante un gran arco elevado sobre cuatro columnas ${ }^{35}$. El alzado del pórtico, como es evidente, no se puede verificar en el plano, pero figura delineado, eso sí, su doble acceso frontal y otro secundario, lateral, que se abría en el costado este. En el lado del evangelio, se localizan otras dos puertas: una comunica con una exigua capilla y la otra con el claustro principal (letra D). También se describe la cabecera plana del templo, donde se ubica un gran tabernáculo cuadrado ("Camaril") que albergaba otro altar más pequeño, fabricado con maderas jaspeadas, que tenía forma circular ${ }^{36}$; y el tramo de escaleras que permitía el acceso al altar. Contigua a la diminuta capilla antes referida, al oeste del presbiterio, se localiza la sacristía; entre estas dos salas -la capilla y la sacristía-, se sitúa un paso cubierto $\left(\mathrm{n}^{\mathrm{o}} 1\right)$ que enlaza la vicaría y el claustro principal (letra D).

A los pies del pórtico de la iglesia, en su lado occidental, se ubica la puerta de entrada a la clausura. El levantamiento de 1835 documenta pormenorizadamente la distribución espacial que tenía el recinto conventual: se organizaba a partir de dos claustros medianos (letra D) que estaban separados por lo que parece ser un corredor cubierto que albergaba escaleras de acceso al piso alto. Alrededor de ambos edificios claustrales, concretamente en los flancos norte, sur y oeste, se disponen varias "celdas altas y bajas" ${ }^{\prime 37}\left(\mathrm{n}^{-} \mathrm{3}\right)$, más pasos cubiertos $\left(\mathrm{n}^{\underline{\mathrm{o}}}\right.$

\footnotetext{
${ }^{35}$ F. GONZÁLEZ DE LEÓN, Op. Cit., p. 449.

${ }^{36}$ Ibidem.

${ }^{37}$ Se distribuían en dos pisos, y eran "estrechas aunque en mucho número pues la comunidad era muy crecida", destacando la pieza de la enfermería y sus oficinas, ori-
} 
1), "salas comunitarias" (n⿳⺈ 8), y otras piezas no identificadas. Al oeste de la huerta, que ocupa la mayor parte del sector norte de la clausura, se localizan más habitaciones ( $\mathrm{n}^{\circ}$ 3) y el refectorio $\left(n^{0} 4\right)$, estancias comunicadas entre sí y con salida al huerto de los monjes. Contiguas al frente que daba a la denominada"calle del hospital del Amor de Dios", es decir, el correspondiente a la fachada oeste del edificio, aparecen situadas algunas dependencias funcionales, que son identificadas por León y Canales como "cocinas y habitaciones necesarias a su uso y corral" (no 5), "puerta del campo con su corral" (no 6) y "cuarto de portero" (nำ7).
Las plantas de los cenobios masculinos de la Santísima Trinidad, San Francisco de Paula y San Pedro de Alcántara responden a una concepción funcional de la arquitectura conventual. Su distribución espacial, más o menos compleja, de acuerdo a las necesidades y los recursos económicos, está orientada a los usos religiosos de los monjes, por supuesto, pero su arquitectura también fue organizada para albergar la vida cotidiana.

gen y principal función de la casa, que por lo visto era "una cuadra muy capaz con divisiones de tabiques para las camas" (Idem, p. 450). 


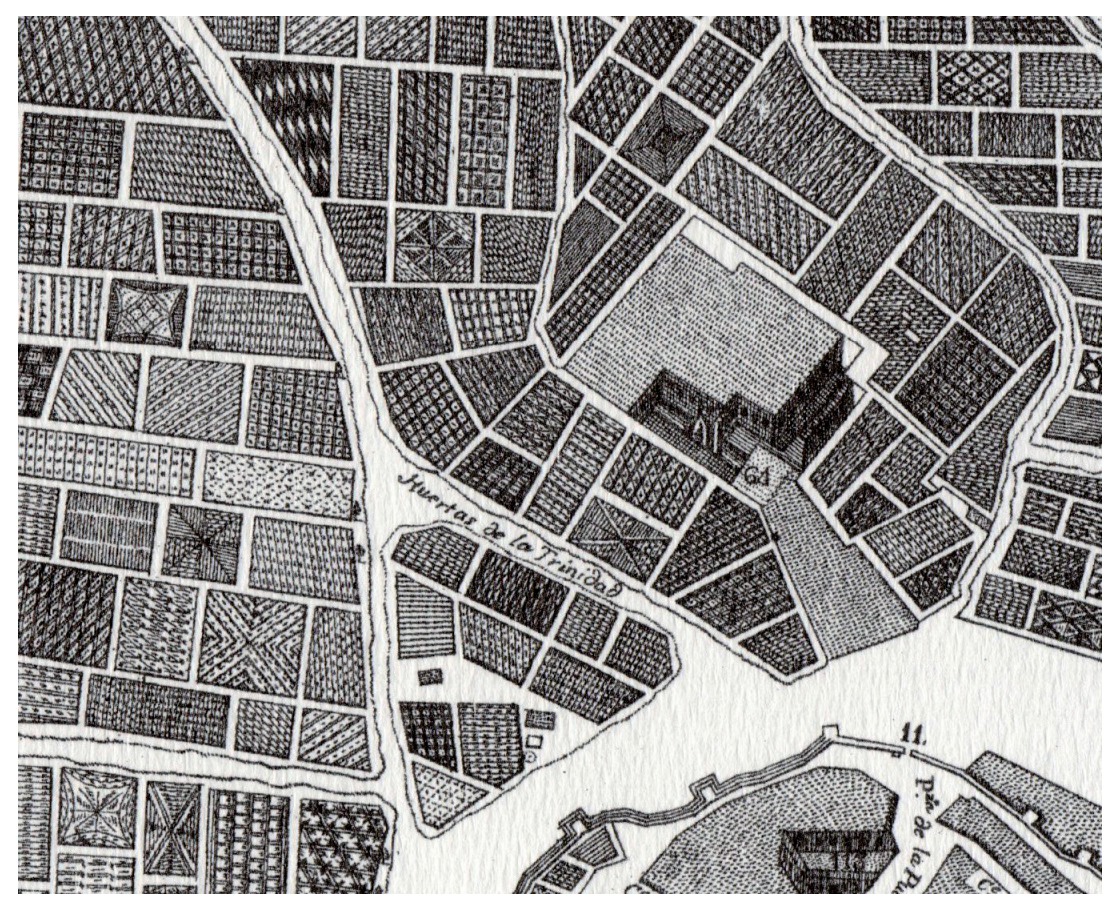

- Fig. 1. El convento de la Santísima Trinidad. F. Coelho y J. Amat. 1771 (AHMS).

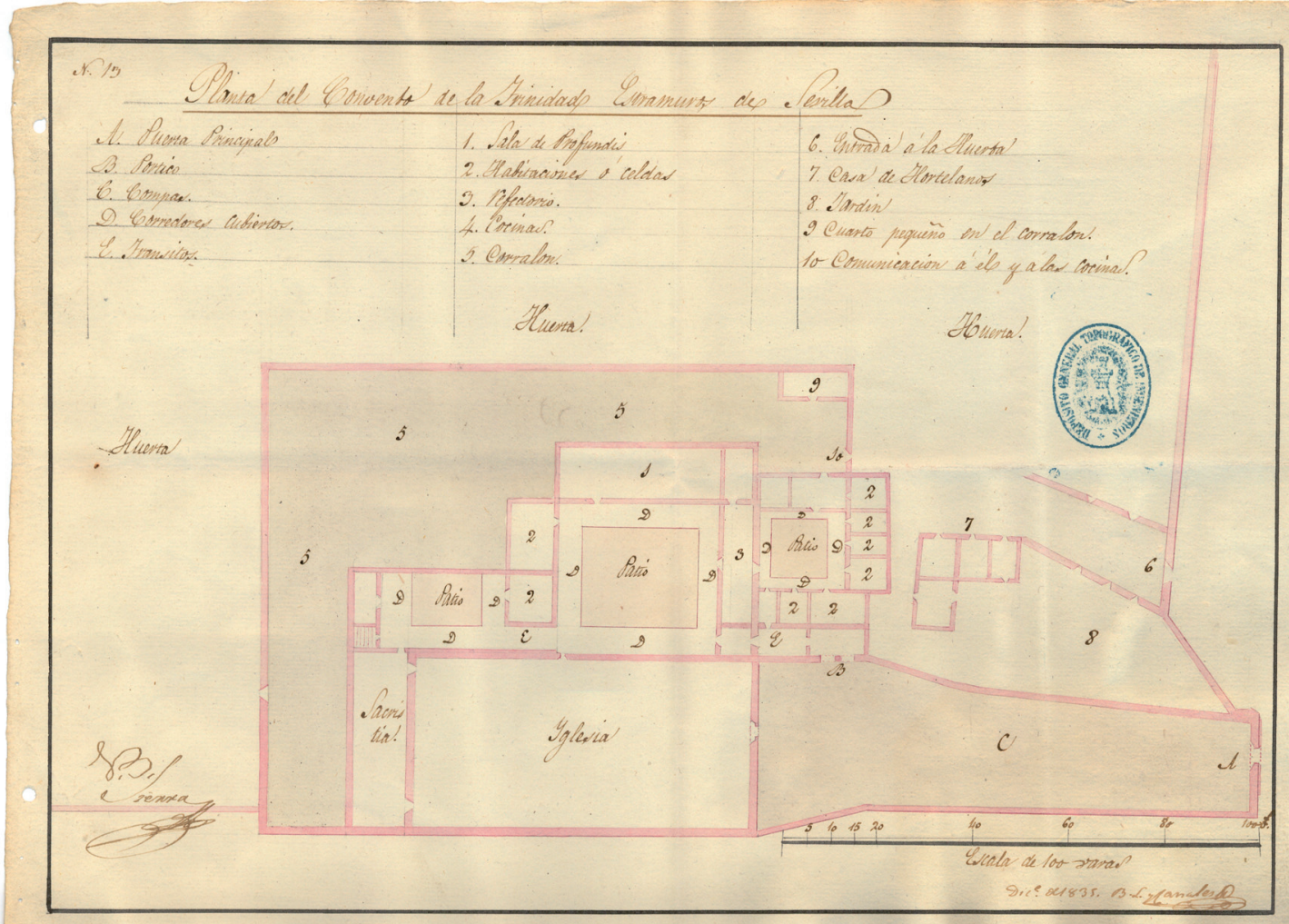

- Fig. 2. Planta del convento de la Trinidad. B. León y Canales. 1835 (AGMM). 


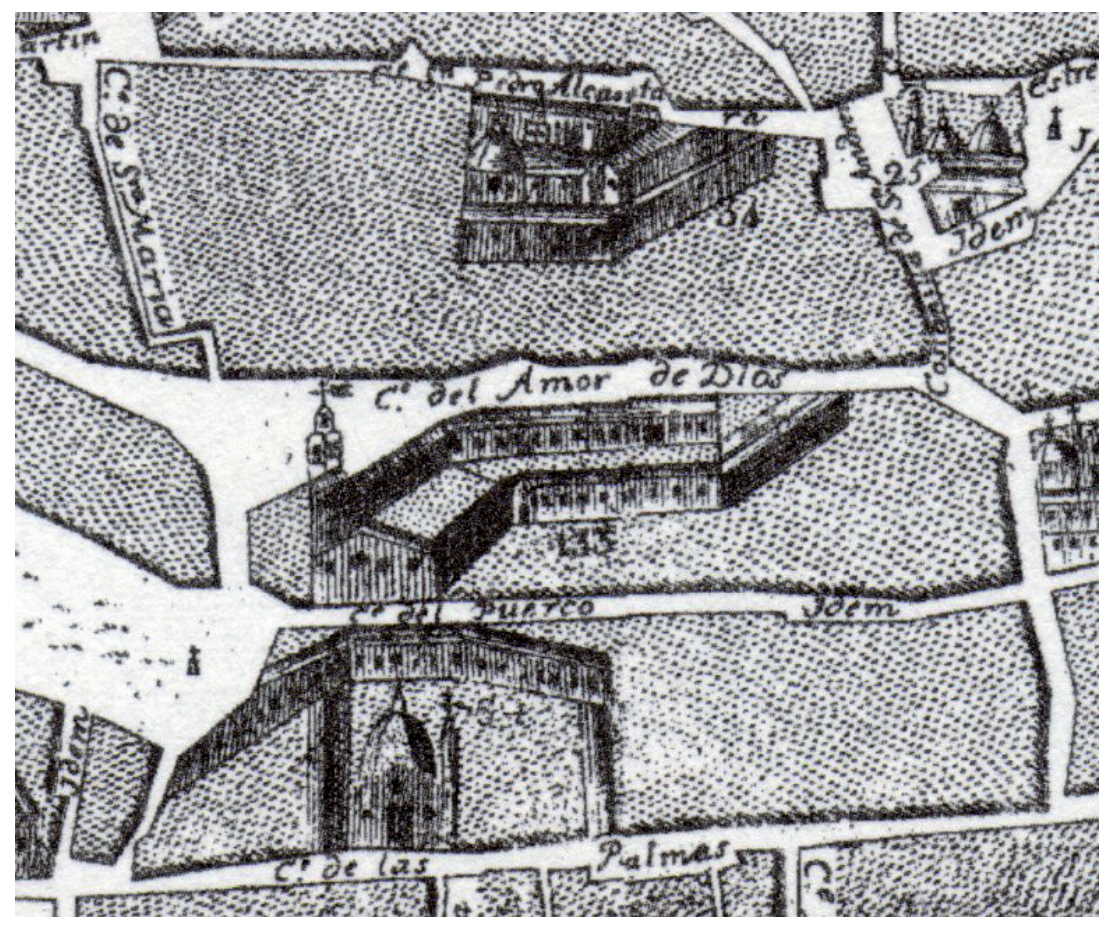

- Fig. 3. Los conventos de San Francisco y San Pedro. F. Coelho y J. Amat. 1771 (AHMS).

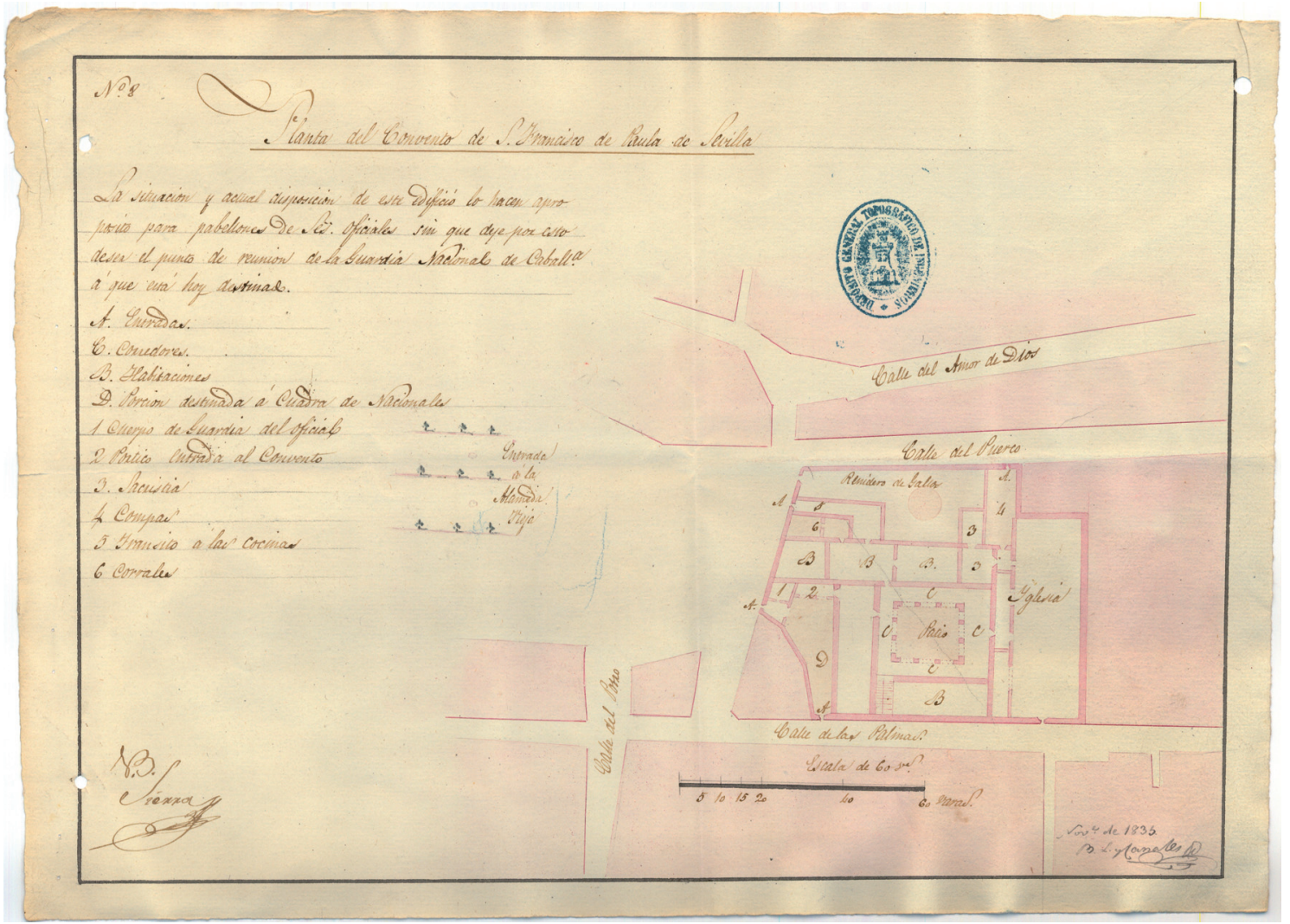

- Fig. 4. Planta del convento de San Francisco de Paula. B. León y Canales. 1835 (AGMM). 


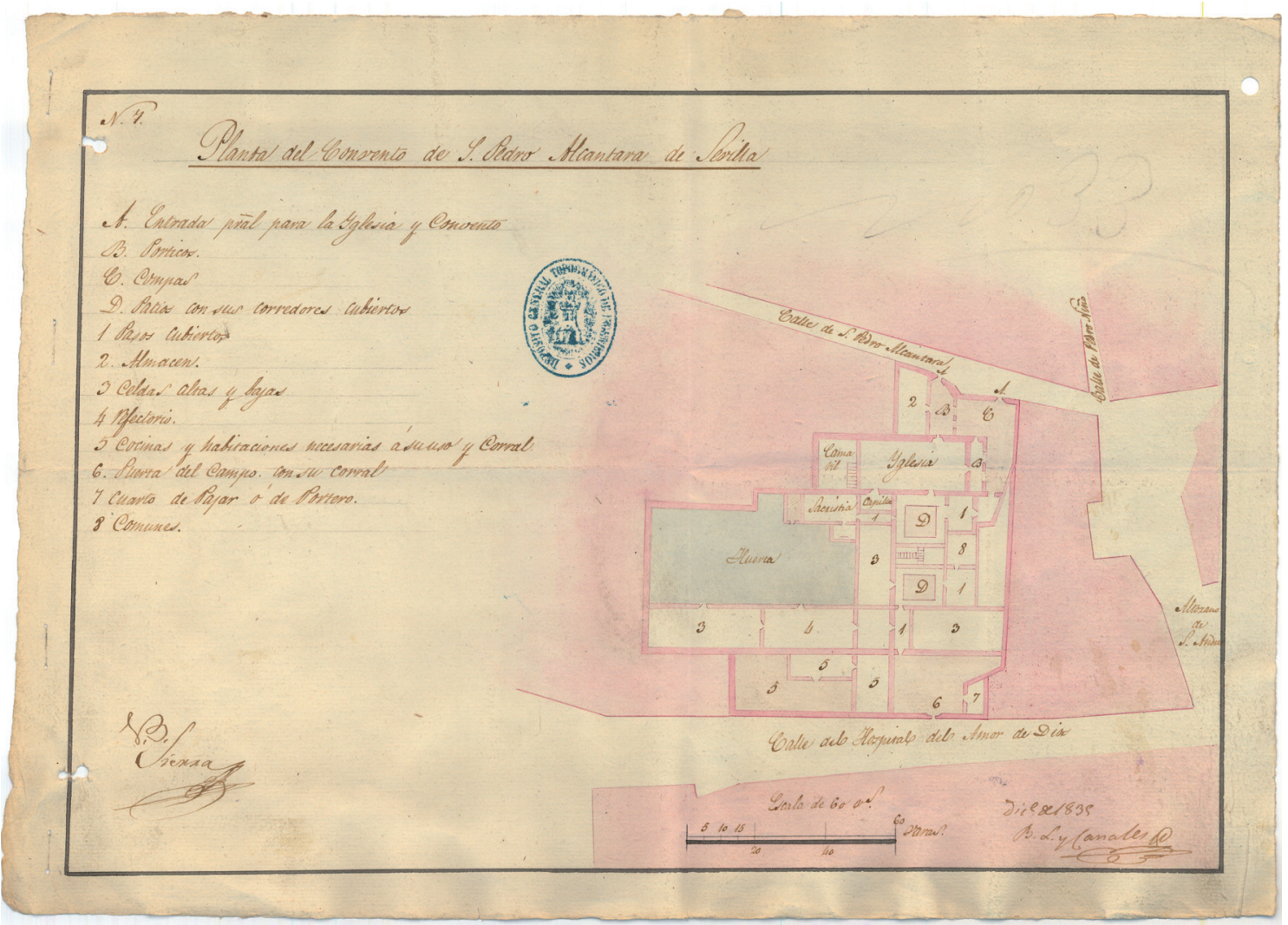

- Fig. 5. Planta del convento de San Pedro de Alcantara. B. León y Canales. 1835 (AGMM). 